\title{
Purification and Partial Characterization of Hepatocyte Growth Factor from Plasma of a Patient with Fulminant Hepatic Failure
}

\author{
Eiichi Gohda, * Hirohito Tsubouchi," Hiroyuki Nakayama," Shuichi Hirono," Osamu Sakiyama," Kozo Takahashi,” \\ Hiroomi Miyazaki, ${ }^{*}$ Shuji Hashimoto, ${ }^{\ddagger}$ and Yasushi Daikuhara* \\ ${ }^{*}$ Department of Biochemistry, Kagoshima University Dental School, and ${ }^{\ddagger}$ the Second Department of Internal Medicine, \\ Faculty of Medicine, Kagoshima University, Kagoshima 890, Japan
}

\begin{abstract}
Human hepatocyte growth factor (hHGF) has been purified $\sim 209,000$-fold with $18 \%$ yield from plasma of a patient with fulminant hepatic failure. The purification involves heat treatment of plasma, ammonium sulfate precipitation, and chromatography on Affi-Gel Blue, heparin-Sepharose, and hydroxylapatite. Purified hHGF shows several bands with molecular weights between 76,000 and 92,000. Each band shows growthstimulating activity on cultured hepatocytes which is proportional to the intensity of the band. After reduction of the sample with 2-mercaptoethanol, SDS-PAGE yields two chains with molecular weights of 31,500-34,500 and 54,000-65,000. The effect of hHGF on DNA synthesis by hepatocytes is halfmaximal at $3.5 \mathrm{ng} / \mathrm{ml}$. hHGF stimulates proliferation of cultured hepatocytes more effectively than human epidermal growth factor (hEGF) or insulin, and the effect of hHGF is additive or synergistic with the maximal effects of hEGF and insulin. These results suggest that hHGF is a new growth factor which is different from hEGF.
\end{abstract}

\section{Introduction}

Patients with fulminant hepatic failure show massive necrosis of liver cells or other sudden and severe impairment of hepatic function (1). Management of the disease is difficult, and mortality of the patients with severe (grade IV) hepatic encephalopathy is still $\sim 80 \%(2,3)$. Liver regeneration is vital to survival of the patients, but nothing is known about the factors controlling this process in the patients. In experimental animals, however, evidence for the presence of a humoral control system for liver regeneration has been reported (4-10), and factors have been isolated (11-17). Recently, Díaz-Gil et al. (18) have purified a factor from plasma of partially hepatectomized rats, and Nakamura et al. (19) have reported purification of a hepatocyte growth factor from rat platelets. These purified factors showed a single band with molecular weights of 64,000 (18) and 27,000 (19) on SDS-polyacrylamide gels, but no evidence was given which confirmed that either of these

This paper is dedicated to Professor Yoshiro Takeda of Tokushima University on the occasion of his retirement.

Address reprint requests to Dr. Daikuhara, Department of Biochemistry, Kagoshima University Dental School, 1208 Usuki-cho, Kagoshima 890, Japan.

Received for publication 29 December 1986 and in revised form 24 August 1987.

J. Clin. Invest.

(C) The American Society for Clinical Investigation, Inc. 0021-9738/88/02/0414/06 \$2.00

Volume 81, February 1988, 414-419 single bands was the factor itself rather than a contaminant. Hepatocyte growth stimulating factors were also isolated from weanling and regenerating rat liver (20-23) and regenerating dog liver $(24,25)$.

We found recently that serum and plasma from patients with fulminant hepatic failure with grade III to IV coma markedly stimulates growth of adult rat hepatocytes in primary culture $(26,27)$, and have partially purified a growth-stimulating factor, human hepatocyte growth factor (hHGF), ${ }^{1}$ from a patient's plasma. It is a heat-labile protein with a molecular weight of $\sim 85,000$ (27). This paper reports the purification and partial characterization of this hHGF.

\section{Methods}

Materials. Collagenase (type I) and insulin were purchased from Sigma Chemical Co., St. Louis, MO. Fetal calf serum was obtained from Filtron, Altona, Australia. Affi-Gel Blue and hydroxylapatite were from Nippon Bio-Rad Laboratories, Tokyo, and heparin-Sepharose CL-6B and molecular weight standards for SDS-PAGE were from Pharmacia Japan Ltd., Tokyo. [Me-- ${ }^{3}$ ] Thymidine $(78.0 \mathrm{Ci} / \mathrm{mmol})$ was obtained from New England Nuclear, Boston, MA. Mouse epidermal growth factor (mEGF) was from Wako Pure Chemical Industries, Osaka, and human epidermal growth factor (hEGF) was from Wakunaga Pharmaceutical Co., Osaka. Plasma was obtained from a patient with fulminant hepatic failure due to hepatitis B (no. 12 described in the previous paper [27]) during plasma exchange therapy and was stored at $-20^{\circ} \mathrm{C}$. Plasma obtained from another patient, no. 13, with non-A, non-B hepatitis gave the same results.

Purification of hHGF from patient's plasma. The first three steps in the purification procedure were essentially the same as described previously (27). A sample of $930 \mathrm{ml}$ of plasma from the patient was subjected to heat treatment and ammonium sulfate fractionation as described (27). The precipitate formed between 1.15 and $2.05 \mathrm{M}$ ammonium sulfate was dissolved in $300 \mathrm{ml}$ of $\mathrm{Ca}^{2+}, \mathrm{Mg}^{2+}$-free phosphatebuffered saline [PBS(-)], dialyzed for $36 \mathrm{~h}$ against three changes of 4 liters of PBS(-), and applied to a column $(3.9 \times 11 \mathrm{~cm})$ of Affi-Gel Blue, equilibrated with PBS(-), at a flow rate of $120 \mathrm{ml} / \mathrm{h}$. The column was washed successively with $250 \mathrm{ml}$ of $\mathrm{PBS}(-)$ and $250 \mathrm{ml}$ of $1.4 \mathrm{M}$ $\mathrm{NaCl}$ in PBS(-) (pH 7.4). The activity of hHGF was then eluted with $350 \mathrm{ml}$ of $2 \mathrm{M}$ guanidine- $\mathrm{HCl}(\mathrm{pH} \mathrm{7.4)}$ at $300 \mathrm{ml} / \mathrm{h}$, and the eluate was dialyzed for $72 \mathrm{~h}$ against at least five changes of 4 liters of PBS( - ).

Concentrated Triton X-100 solution was added to the dialyzed preparation at a final concentration of $0.013 \%$, and the mixture was applied to a heparin-Sepharose column $(1.6 \times 5 \mathrm{~cm})$, equilibrated with $0.013 \%$ Triton X-100 in PBS(-), at a flow rate of $25 \mathrm{ml} / \mathrm{h}$. The column was washed with $75 \mathrm{ml}$ of $0.013 \%$ Triton X-100 in PBS(-) and then with PBS(-) containing $0.5 \mathrm{M} \mathrm{NaCl}$ and $0.013 \%$ Triton X-100 (pH 7.4), until the absorbance of the eluate at $280 \mathrm{~nm}$ reached 0.3 . (This

1. Abbreviations used in this paper: hEGF, human epidermal growth factor; HGF, hepatocyte growth factor; hHGF, human hepatocyte growth factor; mEGF, mouse epidermal growth factor; PBS(-), (Dulbecco's) $\mathrm{Ca}^{2+}, \mathrm{Mg}^{2+}$-free phosphate-buffered saline. 
concentration of Triton X-100 in PBS(-) had an absorbance of 0.21 or greater depending on salt concentration.) The growth-promoting activity was then eluted with a linear salt gradient of $0.5-1.75 \mathrm{M} \mathrm{NaCl}$ in PBS(-) containing $0.013 \%$ Triton X-100 (pH 7.4, total gradient volume, $80 \mathrm{ml}$ ). A single peak of the growth-stimulating activity was eluted at $\sim 1 \mathrm{M} \mathrm{NaCl}$.

Peak fractions from the heparin-Sepharose column were pooled, diluted with an equal volume of $0.013 \%$ Triton X-100 in PBS(-), and applied to a hydroxylapatite column $(1.6 \times 5 \mathrm{~cm})$, equilibrated with $0.013 \%$ Triton X-100 in PBS(-) at a flow rate of $20 \mathrm{ml} / \mathrm{h}$. The column was washed with $20 \mathrm{ml}$ of the same buffer and with $20 \mathrm{ml}$ of $0.1 \mathrm{M}$ sodium phosphate buffer ( $\mathrm{pH} 7.1$ ) containing $0.15 \mathrm{M} \mathrm{NaCl}$ and $0.013 \%$ Triton X-100. The hHGF activity was then eluted with a linear gradient of $0.1-0.5 \mathrm{M}$ sodium phosphate buffer ( $\mathrm{pH} 7.1$ ) containing $0.15 \mathrm{M} \mathrm{NaCl}$ and $0.013 \%$ Triton X-100 (total gradient volume, $60 \mathrm{ml}$ ) at room temperature, and 2-ml fractions were collected. All hHGF activity bound to the column, and there was only one peak of activity eluting between 0.31 and $0.42 \mathrm{M}$ sodium phosphate. Fractions with the highest activity were pooled, passed through a Millex-GV (Millipore Corp., Bedford, MA) filter and kept frozen at $-20^{\circ} \mathrm{C}$.

Primary culture of parenchymal cells from adult rat liver. Parenchymal liver cells were isolated from adult male Wistar rats, weighing $\sim 200 \mathrm{~g}$, by the method of Seglen (28). The cells were plated in Nunc 24-well plastic dishes, unless stated otherwise, at a density of $5 \times 10^{4}$ cells $/ 0.2 \mathrm{ml} \mathrm{per} \mathrm{cm}^{2}$ and were cultured as monolayers at $37^{\circ} \mathrm{C}$ in a humidified atmosphere of $5 \% \mathrm{CO}_{2}$ and $95 \%$ air, essentially as described by Tanaka et al. (29). The culture medium was Williams medium E, supplemented with $5 \%$ fetal calf serum, $1 \mu \mathrm{M}$ dexamethasone, 100 $\mathrm{U} / \mathrm{ml}$ of penicillin, and $100 \mu \mathrm{g} / \mathrm{ml}$ of streptomycin (basal medium). The medium was changed after the first $4 \mathrm{~h}$ and then once a day. Samples were added to the basal medium at the first medium change (4 $\mathrm{h}$ after seeding) and thereafter at each medium change.

Determination of DNA synthesis and autoradiography. The rate of DNA synthesis was determined by pulse-labeling cultured cells with $\left[{ }^{3} \mathrm{H}\right.$ ]thymidine $(4 \mu \mathrm{Ci} / \mathrm{ml}, 2 \mathrm{Ci} / \mathrm{mmol})$ at $37^{\circ} \mathrm{C}$ for $2 \mathrm{~h}$ between 40 and $42 \mathrm{~h}$ after seeding in the presence and absence of $10 \mathrm{mM}$ hydroxyurea as described previously (27). Activity of replicating DNA synthesis was calculated as the difference between the values with and without hydroxyurea. Protein was assayed by the method of Lowry et al. (30) with crystalline bovine serum albumin as standard. For autoradiography, hepatocytes cultured on Lux Thermanox (Miles Laboratories, Inc., Naperville, IL) coverslips were labeled with $\left[{ }^{3} \mathrm{H}\right]$ thymidine $(4 \mu \mathrm{Ci} / \mathrm{ml}$, $2 \mathrm{Ci} / \mathrm{mmol}$ ) between 25 and $50 \mathrm{~h}$ after seeding. Autoradiograms of the hepatocytes were prepared as described previously (26), except that the cells were fixed in PBS(-)/methanol/glacial acetic acid (4:3:1 by vol) and then in methanol/glacial acetic acid (3:1 by vol) (31). At least 250 cells in randomly selected fields of a coverslip were examined to determine the labeling index, which was expressed as the percentage of the nuclei heavily labeled with $\left[{ }^{3} \mathrm{H}\right]$ thymidine.

$S D S-P A G E$. SDS-PAGE was performed at room temperature by the method of Laemmli (32) using a 3\% stacking gel and a $8 \%$ or $13.5 \%$ separating gel $1 \mathrm{~mm}$ thick. Samples were prepared by mixing with an equal volume of buffer consisting of $125 \mathrm{mM}$ Tris- $\mathrm{HCl}$ (pH 6.8), 6\% SDS, $20 \%$ glycerol (vol/vol), and $0.0025 \%$ bromphenol blue in the presence or absence of 1\% 2-mercaptoethanol and boiled for $5 \mathrm{~min}$ before use, unless stated otherwise. In the case of reduced samples, they were further alkylated with iodoacetamide at a concentration three times greater than that of 2-mercaptoethanol to reduce artifact bands observed upon silver staining. After electrophoresis, gels were fixed in $10 \%$ trichloroacetic acid overnight (8\% separating gel) or in methanol/ glacial acetic acid/water (5:1:4 by vol) for at least $30 \mathrm{~min}$ followed by overnight washing in a solution consisting of 5\% methanol and 7\% acetic acid in water (13.5\% separating gel) (33). The gels were silverstained by the method of Wray et al. (34). Molecular weight standards used for SDS-PAGE were phosphorylase b $(94,000 \mathrm{~mol} \mathrm{wt})$, bovine serum albumin $(67,000)$, ovalbumin $(43,000)$, carbonic anhydrase $(30,000)$, soybean trypsin inhibitor $(20,100)$, and $\alpha$-lactalbumin $(14,400)$.
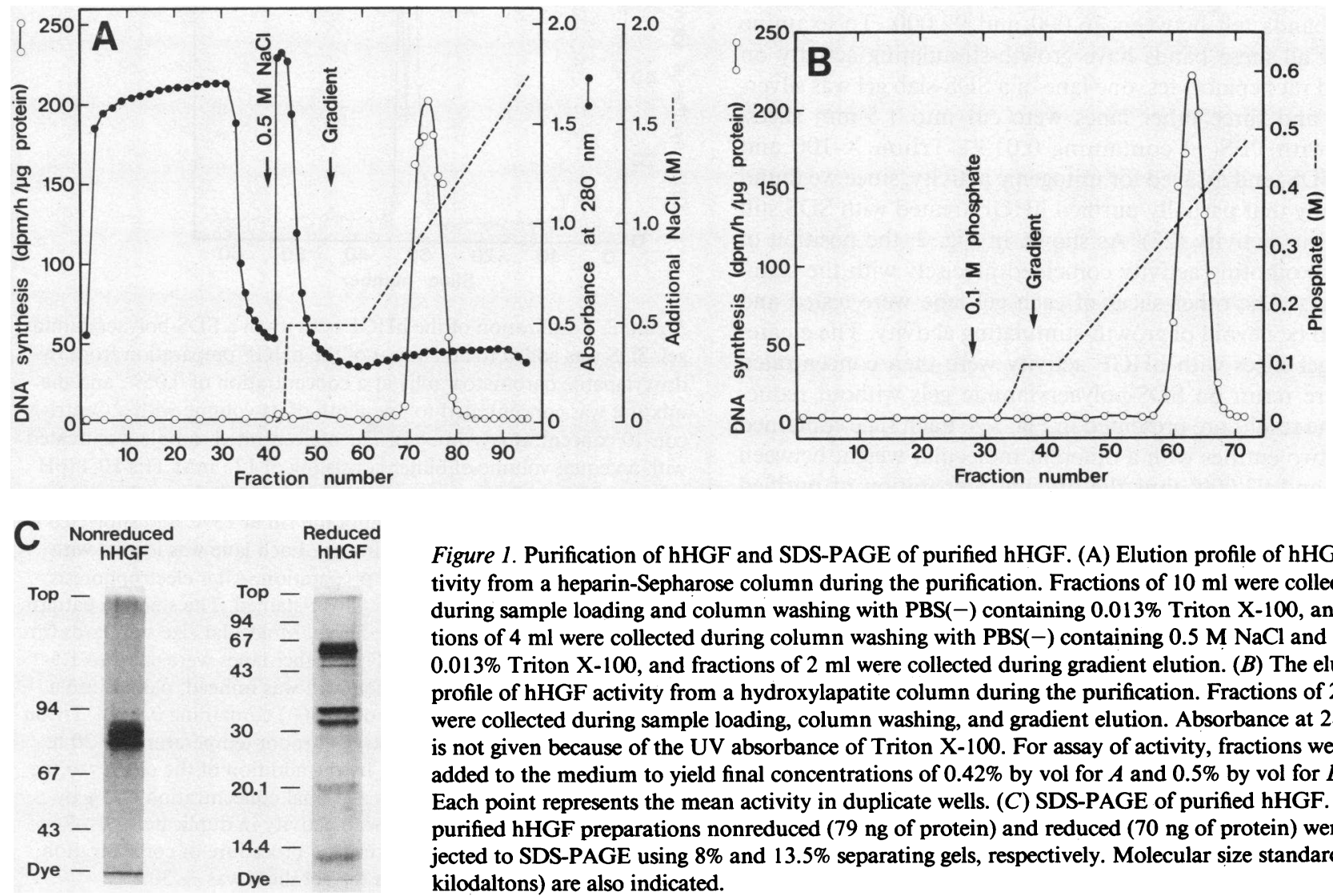

Figure 1. Purification of hHGF and SDS-PAGE of purified hHGF. (A) Elution profile of hHGF activity from a heparin-Sepharose column during the purification. Fractions of $10 \mathrm{ml}$ were collected during sample loading and column washing with PBS(-) containing $0.013 \%$ Triton X-100, and fractions of $4 \mathrm{ml}$ were collected during column washing with PBS(-) containing $0.5 \mathrm{M} \mathrm{NaCl}$ and $0.013 \%$ Triton $X-100$, and fractions of $2 \mathrm{ml}$ were collected during gradient elution. $(B)$ The elution profile of hHGF activity from a hydroxylapatite column during the purification. Fractions of $2 \mathrm{ml}$ were collected during sample loading, column washing, and gradient elution. Absorbance at $280 \mathrm{~nm}$ is not given because of the UV absorbance of Triton X-100. For assay of activity, fractions were added to the medium to yield final concentrations of $0.42 \%$ by vol for $A$ and $0.5 \%$ by vol for $B$. Each point represents the mean activity in duplicate wells. $(C)$ SDS-PAGE of purified hHGF. The purified hHGF preparations nonreduced (79 $\mathrm{ng}$ of protein) and reduced (70 $\mathrm{ng}$ of protein) were subjected to SDS-PAGE using $8 \%$ and $13.5 \%$ separating gels, respectively. Molecular size standards (in kilodaltons) are also indicated. 
Table I. Purification of $h H G F$

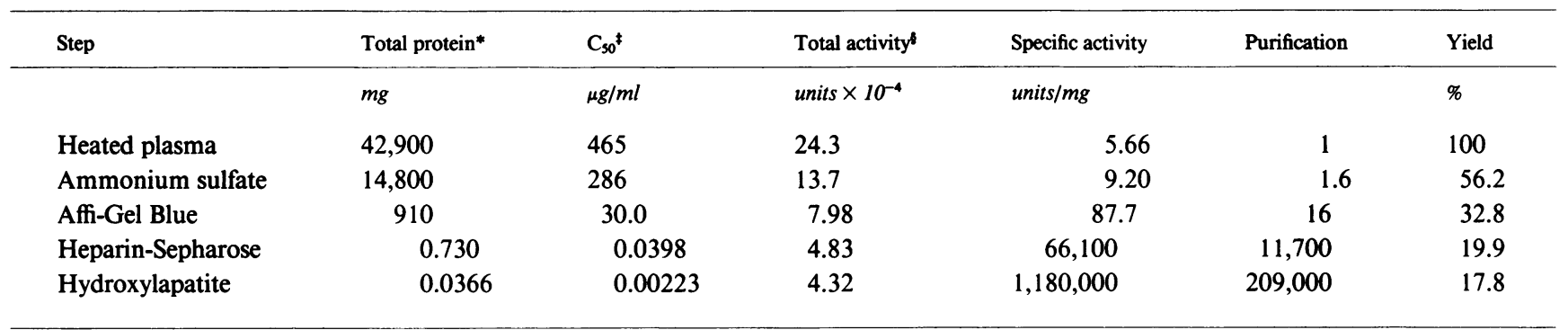

* Protein was determined by a modification (35) of the method of Lowry et al. (30), using crystalline bovine serum albumin as a standard. ₹ The protein concentration of a hHGF preparation required for $50 \%$ of the maximal response to mEGF. ${ }^{\S}$ One unit of activity is defined as the quantity of hHGF required for $50 \%$ of the maximal response to mEGF in the assay system described.

\section{Results}

The purification procedure described here consists of five steps. The elution profiles of hHGF activity from columns of heparin-Sepharose and hydroxylapatite are shown in Fig. 1, $A$ and $B$, respectively. All hHGF activity bound to both columns, and only one peak of activity was observed to elute in each case. Results of a typical purification are summarized in Table I. Starting with $930 \mathrm{ml}$ of plasma from a patient, we obtained $37 \mu \mathrm{g}$ of hHGF, respresenting a 209,000-fold purification and a $18 \%$ yield. The most effective step was heparinSepharose chromatography which produced a 750 -fold increase in the specific activity.

The final preparation revealed several bands detectable with silver stain after SDS-PAGE under nonreducing conditions (Figs. $1 C$ and 2). The two major bands had molecular weights of 79,000 and 86,000 while the molecular weight of the minor bands fell between 76,000 and 92,000 . To examine whether all these bands have growth-stimulating activity on cultured rat hepatocytes, one lane of a SDS-slab gel was silverstained and three other lanes were cut into $1.5-\mathrm{mm}$ slices, eluted with PBS(-) containing $0.013 \%$ Triton X-100 and $0.02 \%$ SDS, and assayed for mitogenic activity, since we found previosuly that partially purified hHGF treated with SDS still retained its activity (27). As shown in Fig. 2, the position of growth-promoting activity coincided precisely with the staining bands. The other slices of each gel lane were tested and found to be devoid of growth-stimulating activity. The eluates of the gel slices with hHGF activity were then concentrated and were rerun on SDS-polyacrylamide gels without reduction. The results are presented in Fig. $3 \mathrm{~A}$. Each slice contained one or two entities with a different molecular weight between 76,000 and 92,000 ; thus the original preparation of purified hHGF consisted of at least seven different molecular weight entities. The potency of the growth-promoting activity of the eluates paralleled the darkness of stained bands. These results suggest that all bands are different molecular weight forms of hHGF rather than contaminants.

When purified hHGF was reduced with 2-mercaptoethanol and subjected to SDS-PAGE, one major group of bands with molecular weight between 54,000 and 65,000 , two major bands with molecular weights of 31,500 and 34,500 , and at least three minor bands with molecular weights of 48,000 , 21,000 , and 13,000 were detected on silver staining (Fig. 1C). The eluted and concentrated fractions from the slices of nonreduced SDS-gels described above were rerun on SDS-gels after reduction. As presented in Fig. $3 B$, the eluates of all slices (nos. 29-34) with hHGF activity showed two groups of bands with molecular weights of 54,000-65,000 and 31,500-34,500. Judging from both this result and the above finding that molecular weights of nonreduced hHGF were in the range of

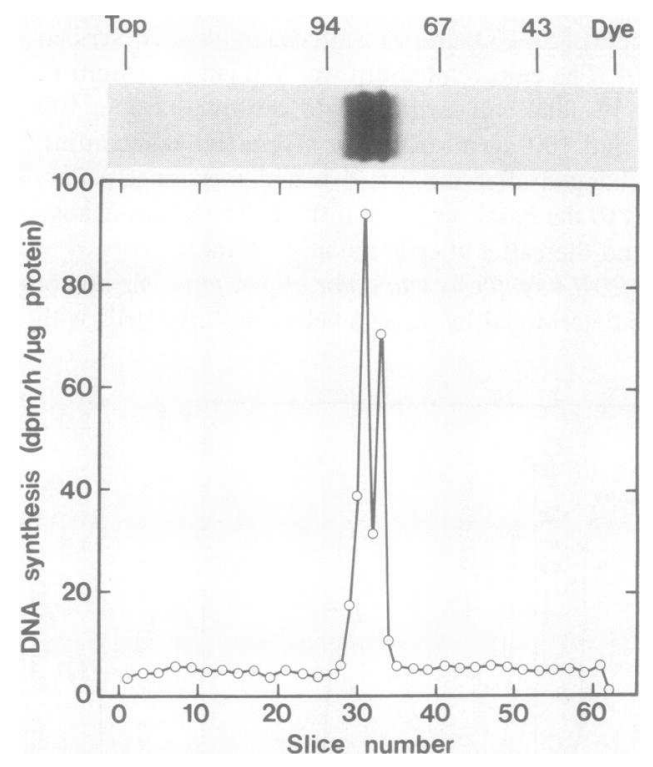

Figure 2. Localization of the hHGF activity in a SDS-polyacrylamide gel. SDS was added to an aliquot of the hHGF preparation from hydroxylapatite chromatography at a concentration of $0.05 \%$, and the mixture was concentrated to one-tenth of its volume with a Centricon-10 concentrator (Amicon). The concentrated sample was treated with an equal volume of buffer consisting of $125 \mathrm{mM}$ Tris- $\mathrm{HCl}(\mathrm{pH}$ 6.8 ), $6 \%$ SDS, $20 \%$ glycerol (vol/vol) and $0.0025 \%$ bromphenol blue in the absence of 2-mercaptoethanol for $1 \mathrm{~h}$ at $25^{\circ} \mathrm{C}$ and subjected to SDS-PAGE using an $8 \%$ separating gel. Each lane was loaded with $20 \mu$ lof the concentrated hHGF preparation. After electrophoresis, one lane of the separating gel was silver-stained. The staining pattern is shown in the upper part of the figure. Molecular size standards (in kilodaltons) are also indicated. Three other lanes were cut into 1.5$\mathrm{mm}$ slices with a razor blade. Each slice was minced, placed into a test tube, and incubated at $1 \mathrm{ml}$ of PBS(-) containing $0.013 \%$ Triton $\mathrm{X}-100$ and $0.02 \%$ SDS with shaking at room temperature for $20 \mathrm{~h}$. hHGF activity was then assayed by the addition of the eluates to the medium of cultured hepatocytes at a final concentration of $5 \%$ by vol. Each point represents the mean activity in duplicate wells. Recovery of the hHGF activity during the procedure of concentration, electrophoresis and elution from the gel slices was $\sim 30 \%$. 


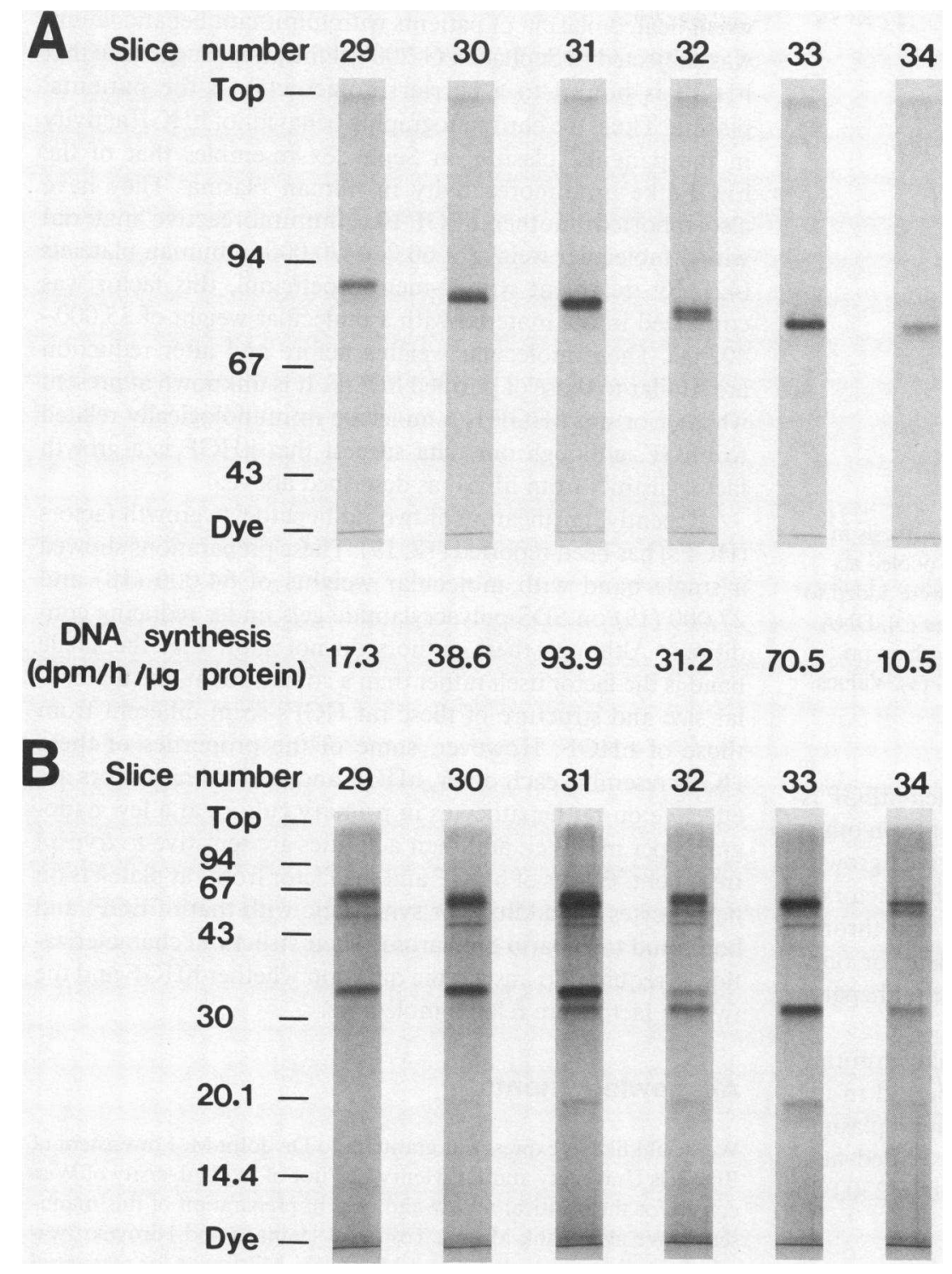




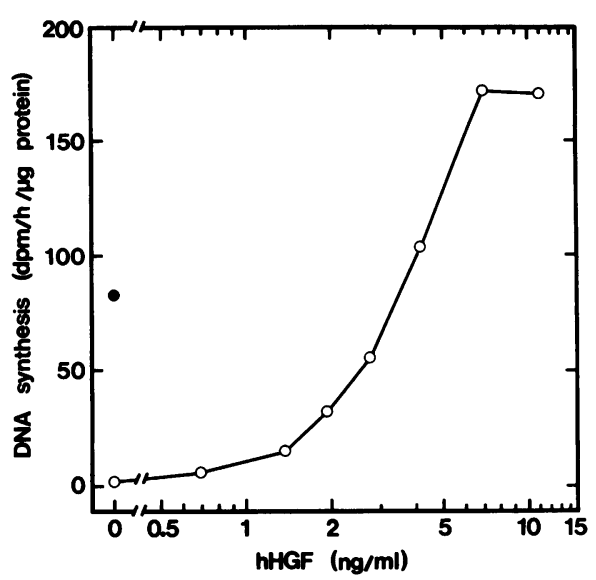

Figure 4. Dose-response curve for stimulation of DNA synthesis in cultured rat hepatocytes by hHGF. Various doses of the pooled active fractions of hHGF from a hydroxylapatite column were added to cultured hepatocytes, and DNA synthesis was determined (o). DNA synthesis in hepatocytes cultured in the basal medium with an optimal concentration of $\mathrm{mEGF}(25 \mathrm{ng} / \mathrm{ml})$ are also shown $(\bullet)$. Values are means for duplicate wells.

cells (Gohda et al., unpublished observations), which mEGF is known to enhance (37). hHGF seems also different from other well-known growth factors, including platelet-derived growth factor, fibroblast growth factor, insulinlike growth factors I and II, transforming growth factor- $\beta$, transferrin, and thrombin, because these factors inhibit, do not stimulate, or only slightly stimulate DNA synthesis in cultured adult rat hepatocytes $(12,19,38-40)$.

Kurobe et al. (41) have recently found hEGF-like immunoreactivity with high molecular weight, which emerged in the void volume of a Sephadex G-100 column, in human plasma. As we reported previously (27), hHGF activity eluted at a position corresponding to a molecular weight of $\sim 230,000$

Table II. Effects of Insulin, hHGF, and hEGF on DNA Synthesis and Labeling Index of Cultured Hepatocytes

\begin{tabular}{llll}
\hline $\begin{array}{l}\text { Addition to the } \\
\text { basal medium }\end{array}$ & Concentration & DNA synthesis & Labeling index* \\
\hline & $n g / m l$ & $\begin{array}{l}\text { dpm/h per } \mu g \\
\text { protein }\end{array}$ & $\%$ \\
& & $1.7 \pm 0.4^{\ddagger}$ & $<0.2^{\ddagger}$ \\
None & - & $7.8 \pm 0.8$ & 4.1 \\
Insulin & 600 & $42.7 \pm 3.3$ & 9.2 \\
hEGF & 2.1 & $175.4 \pm 3.3$ & $24.7 \pm 7.7$ \\
& 6.3 & $197.2 \pm 3.1$ & $31.7 \pm 3.4$ \\
& 9.4 & $297.9 \pm 19.4$ & $50.1 \pm 1.2$ \\
hHGF & 8.3 & $578.9 \pm 47.2$ & 66.8 \\
hHGF + hEGF & $8.3+6.3$ & $569.1 \pm 3.2$ & 64.0 \\
& $8.3+9.4$ & $503.9 \pm 6.5$ & $63.1 \pm 5.6$ \\
Insulin + hEGF & $600+6.3$ & $461.5 \pm 21.6$ & $77.9 \pm 5.3$ \\
Insulin + hHGF & $600+8.3$ & & \\
Insulin + hHGF & & $684.0 \pm 41.0$ & $85.0 \pm 4.0$ \\
$\quad$ + hEGF & $600+8.3+6.3$ & 6 &
\end{tabular}

\footnotetext{
* Linbro 12-well plastic dishes were used for culture of hepatocytes instead of Nunc dishes.

$¥$ Values are means \pm SD for triplicate wells or means for duplicate wells.
}

when heated plasma of patients with fulminant hepatic failure was subjected to Sephadex G-200 gel filtration, suggesting that hHGF is bound to a carrier molecule(s) in the patients' plasma. Thus, the chromatographic behavior of hHGF activity in the patients' plasma on Sephadex resembles that of the hEGF-like immunoreactivity in human plasma. They have also reported another hEGF-like immunoreactive material with a molecular weight of $60,000-70,000$ in human platelets (42). By treatment with 2-mercaptoethanol, this factor was converted into a material with a molecular weight of 35,000 40,000 . These molecular weights before and after reduction are similar to those of purified hHGF. It is unknown at present whether or not hHGF is a molecule immunologically related to hEGF, although our data suggest that hHGF is a growth factor distinct from $\mathrm{hEGF}$ as described above.

Recently, purification of two rat hepatocyte growth factors (HGFs) has been reported $(18,19)$. These preparations showed a single band with molecular weights of 64,000 (18) and 27,000 (19) on SDS-polyacrylamide gels under reducing conditions. Although these authors do not show that the single band is the factor itself rather than a contaminant, the molecular size and structure of these rat HGFs seem different from those of hHGF. However, some of the properties of these HGFs resemble each other. hHGF and the two rat factors are effective on rat hepatocytes in primary culture at a few nanograms per milliliter, and their activities are sensitive to trypsin treatment. Effects of hHGF and the factor from rat platelets on hepatocytes are additive or synergistic with that of EGF, and both bind to heparin-Sepharose. Their structural characterization is required to answer the question whether hHGF and the two rat factors are related molecules.

\section{Acknowledgments}

We would like to express our gratitude to Dr. John M. Lowenstein of Brandeis University and Dr. Henry C. Pitot of the University of Wisconsin for their critical review and help in preparation of this manuscript. We also thank Messrs. Toshitaka Hamada and Hiroyuki Iwasaki for technical assistance and Miss Maki Mitsunaga for secretarial assistance.

This work was supported in part by Grants-in-Aid for Scientific Research (Nos. 59570792, 60570297, and 61480190) from the Ministry of Education, Science and Culture of Japan.

\section{References}

1. Trey, C., and C. S. Davidson. 1970. The management of fulminant hepatic failure. Prog. Liver Dis. 3:282-298.

2. Jenkins, P. J., and R. Williams. 1980. Fulminant viral hepatitis. Clin. Gastroenterol. 9:171-189.

3. Sherlock, D. S. 1981. Diseases of the Liver and Biliary System. 6th ed. Blackwell Scientific Publications, Oxford. 107-115.

4. Moolten, F. L., and N. L. R. Bucher. 1967. Regeneration of rat liver: transfer of humoral agent by cross circulation. Science (Wash. DC). 158:272-274.

5. Sakai, A. 1970. Humoral factor triggering DNA synthesis after partial hepatectomy in the rat. Nature (Lond.). 228:1186-1187.

6. Fisher, B., P. Szuch, M. Levine, and E. R. Fisher. 1971. A portal blood factor as the humoral agent in liver regeneration. Science (Wash. DC). 171:575-577.

7. Short, J., R. F. Brown, A. Husakova, J. R. Gilbertson, R. Zemel, and I. Lieberman. 1972. Induction of deoxyribonucleic acid synthesis in the liver of the intact animal. J. Biol. Chem. 247:1757-1766.

8. Paul, D., H. Leffert, G. Sato, and R. W. Holley. 1972. Stimula- 
tion of DNA and protein synthesis in fetal-rat liver cells by serum from partially hepatectomized rats. Proc. Natl. Acad. Sci. USA. 69:374-377.

9. Morley, C. G. D., and J. L. Boyer. 1977. Stimulation of hepatocellular proliferation by a serum factor from thioacetamide-treated rats. Biochim. Biophys. Acta. 477:165-176.

10. Michalopoulos, G., H. D. Cianciulli, A. R. Novotny, A. D. Kligerman, S. C. Strom, and R. L. Jirtle. 1982. Liver regeneration studies with rat hepatocytes in primary culture. Cancer Res. 42:46734682.

11. Morley, C. G. D., and H. S. Kingdon. 1973. The regulation of cell growth. I. Identification and partial characterization of a DNA synthesis stimulating factor from the serum of partially hepatectomized rats. Biochim. Biophys. Acta. 308:260-275.

12. Nakamura, T., K. Nawa, and A. Ichihara. 1984. Partial purification and characterization of hepatocyte growth factor from serum of hepatectomized rats. Biochem. Biophys. Res. Commun. 122:14501459.

13. Michalopoulos, G., K. A. Houck, M. L. Dolan, and N. C. Luetteke. 1984. Control of hepatocyte replication by two serum factors. Cancer Res. 44:4414-4419.

14. Russell, W. E., J. A. McGowan, and N. L. R. Bucher, 1984. Partial characterization of a hepatocyte growth factor from rat platelets. J. Cell. Physiol. 119:183-192.

15. Russell, W. E., J. A. McGowan, and N. L. R. Bucher. 1984. Biological properties of a hepatocyte growth factor from rat platelets. $J$. Cell. Physiol. 119:193-197.

16. Thaler, F. J., and G. K. Michalopoulos. 1985. Hepatopoietin A: partial characterization and trypsin activation of a hepatocyte growth factor. Cancer Res. 45:2545-2549.

17. Goldberg, M. 1985. Purification and partial characterization of a liver cell proliferation factor called hepatopoietin. J. Cell. Biochem. 27:291-302.

18. Díaz-Gil, J. J., P. Escartín, R. García-Cañero, C. Trilla, J. J. Veloso, G. Sánchez, A. Moreno-Caparrós, C. Enrique De Salamanca, R. Lozano, J. G. Gavilanes, and J. M. García-Segura. 1986. Purification of a liver DNA-synthesis promoter from plasma of partially hepatectomized rats. Biochem. J. 235:49-55.

19. Nakamura, T., H. Teramoto, and A. Ichihara. 1986. Purification and characterization of a growth factor from rat platelets for mature parenchymal hepatocytes in primary cultures. Proc. Natl. Acad. Sci. USA. 83:6489-6493.

20. Demetriou, A. A., and S. M. Levenson. 1978. Production of a hepatocyte growth-stimulating factor by the regenerating liver. Gastroenterology. 75:959. (Abstr.)

21. LaBrecque, D. R., and N. R. Bachur. 1982. Hepatic stimulator substance: physicochemical characteristics and specificity. Am. J. Physiol. 242:G281-G288.

22. LaBrecque, D. R. 1982. In vitro stimulation of cell growth by hepatic stimulator substance. Am. J. Physiol. 242:G289-G295.

23. LaBrecque, D. R., G. Steele, and S. Fogerty. 1983. Further purification of hepatic stimulator substance (HSS): a liver specific growth factor. Fed. Proc. 42:1832. (Abstr.)

24. Starzl, T. E., A. F. Jones, J. Terblanche, S. Usui, K. A. Porter, and G. Mazzoni. 1979. Growth-stimulating factor in regenerating canine liver. Lancet. 1:127-130.
25. Starzl, T. E., K. A. Porter, N. Hayashida, P. Schechter, and J. Terblanche. 1980. Further studies on hepatic stimulatory substance (SS) after partial hepatectomy. J. Surg. Res. 29:471-474.

26. Nakayama, H., H. Tsubouchi, E. Gohda, M. Koura, J. Nagahama, H. Yoshida, Y. Daikuhara, and S. Hashimoto. 1985. Stimulation of DNA synthesis in adult rat hepatocytes in primary culture by sera from patients with fulminant hepatic failure. Biomed. Res. 6:231-237.

27. Gohda, E., H. Tsubouchi, H. Nakayama, S. Hirono, K. Takahashi, M. Koura, S. Hashimoto, and Y. Daikuhara. 1986. Human hepatocyte growth factor in plasma from patients with fulminant hepatic failure. Exp. Cell Res. 166:139-150.

28. Seglen, P. O. 1976. Preparation of isolated rat liver cells. Methods Cell Biol. 13:29-83.

29. Tanaka, K., M. Sato, Y. Tomita, and A. Ichihara. 1978. Biochemical studies on liver functions in primary cultured hepatocytes of adult rats. I. Hormonal effects on cell viability and protein synthesis. $J$. Biochem. (Tokyo). 84:937-946.

30. Lowry, O. H., N. J. Rosebrough, A. L. Farr, and R. J. Randall. 1951. Protein measurement with the Folin phenol reagent. J. Biol. Chem. 193: 265-275.

31. Stein, G. H., and R. Yanishevsky. 1979. Autoradiography. Methods Enzymol. 58:279-292.

32. Laemmli, U. K. 1970. Cleavage of structural proteins during the assembly of the head of bacteriophage T4. Nature (Lond.). 227:680-685.

33. Oakley, B. R., D. R. Kirsch, and N. R. Morris. 1980. A simplified ultrasensitive silver stain for detecting proteins in polyacrylamide gels. Anal. Biochem. 105:361-363.

34. Wray, W., T. Boulikas, V. P. Wray, and R. Hanocock. 1981. Silver staining of proteins in polyacrylamide gels. Anal. Biochem. 118:197-203.

35. Bensadoun, A., and D. Weinstein. 1976. Assay of proteins in the presence of interfering materials. Anal. Biochem. 70:241-250.

36. Gregory, H. 1975. Isolation and structure of urogastrone and its relationship to epidermal growth factor. Nature (Lond.). 257:325-327.

37. Rose, S. P., R. M. Pruss, and H. R. Herschman. 1975. Initiation of 3T3 fibroblast cell division by epidermal growth factor. J. Cell. Physiol. 86:593-598.

38. Koch, K. S., P. Shapiro, H. Skelly, and H. L. Leffert. 1982. Rat hepatocyte proliferation is stimulated by insulin-like peptides in defined medium. Biochem. Biophys. Res. Commun. 109:1054-1060.

39. Hayashi, I., and B. I. Carr. 1985. DNA synthesis in rat hepatocytes: inhibition by a platelet factor and stimulation by an endogenous factor. J. Cell. Physiol. 125:82-90.

40. Nakamura, T., Y. Tomita, R., Hirai, K. Yamaoka, K. Kaji, and A. Ichihara. 1985. Inhibitory effect of transforming growth factor- $\beta$ on DNA synthesis of adult rat hepatocytes in primary culture. Biochem. Biophys. Res. Commun. 133:1042-1050.

41. Kurobe, M., S. Furukawa, and K. Hayashi. 1986. Molecular nature of human epidermal growth factor (hEGF)-like immunoreactivity in human plasma. Biochem. Int. 12:677-683.

42. Kurobe, M., N. Tokida, S. Furukawa, and K. Hayashi. 1986. Some properties of human epidermal growth factor (hEGF)-like immunoreactive material originating from platelets during blood coagulation. Biochem. Int. 13:729-733. 